\title{
Novel Use of a Lipid-Lowering Fibrate Medication to Prevent Nicotine Reward and Relapse: Preclinical Findings
}

\author{
Leigh V Panlilio', Zuzana Justinova',2, Paola Mascia', Marco Pistis ${ }^{3}$, Antonio Luchicchi $^{3}$, Salvatore Lecca ${ }^{3}$, \\ Chanel Barnes', Godfrey H Redhi', Jordan Adair ${ }^{1,2}$, Stephen J Heishman ${ }^{4}$, Sevil Yasar ${ }^{5}$, Mano Aliczki ${ }^{6}$, \\ Jozsef Haller ${ }^{6}$ and Steven R Goldberg*, I \\ IIntramural Research Program, Preclinical Pharmacology Section, Department of Health and Human Services, National Institute on Drug Abuse, \\ National Institutes of Health, Baltimore, MD, USA; ${ }^{2}$ Department of Psychiatry, Maryland Psychiatric Research Center, University of Maryland \\ School of Medicine, Baltimore, MD, USA; ${ }^{3}$ BB Brodie Department of Neuroscience, University of Cagliari, Cagliari, Italy; ${ }^{4}$ Intramural Research \\ Program, Nicotine Psychopharmacology Section, Department of Health and Human Services, National Institute on Drug Abuse, National \\ Institutes of Health, Baltimore, MD, USA; ${ }^{5}$ Division of Geriatric Medicine and Gerontology, Johns Hopkins University School of Medicine, \\ Baltimore, MD, USA; ${ }^{6}$ Department of Behavioral Neuroscience, Institute of Experimental Medicine, Hungarian Academy of Science, Budapest, \\ Hungary
}

\begin{abstract}
Experimental drugs that activate $\alpha$-type peroxisome proliferator-activated receptors (PPAR $\alpha$ ) have recently been shown to reduce the rewarding effects of nicotine in animals, but these drugs have not been approved for human use. The fibrates are a class of PPAR $\alpha$-activating medications that are widely prescribed to improve lipid profiles and prevent cardiovascular disease, but these drugs have not been tested in animal models of nicotine reward. Here, we examine the effects of clofibrate, a representative of the fibrate class, on reward-related behavioral, electrophysiological, and neurochemical effects of nicotine in rats and squirrel monkeys. Clofibrate prevented the acquisition of nicotine-taking behavior in naive animals, substantially decreased nicotine taking in experienced animals, and counteracted the relapse-inducing effects of re-exposure to nicotine or nicotine-associated cues after a period of abstinence. In the central nervous system, clofibrate blocked nicotine's effects on neuronal firing in the ventral tegmental area and on dopamine release in the nucleus accumbens shell. All of these results suggest that fibrate medications might promote smoking cessation. The fact that fibrates are already approved for human use could expedite clinical trials and subsequent implementation of fibrates as a treatment for tobacco dependence, especially in smokers with abnormal lipid profiles.

Neuropsychopharmacology (2012) 37, 1838-1847; doi:I0.1038/npp.2012.31; published online 28 March 2012
\end{abstract}

Keywords: nicotine; reward; relapse; dopamine signaling; PPAR $\alpha$; fibrate

\section{INTRODUCTION}

Smoking is the leading preventable cause of death, killing nearly six million people per year (World Health Organization, 2011). About $30 \%$ of smoking-attributable mortality is due to cardiovascular disease (Centers for Disease Control and Prevention, 2008). Smoking cessation substantially lowers the risk of mortality in people with coronary heart disease (Critchley and Capewell, 2003), and currently available medications (nicotine replacement, bupropion, and varenicline) increase the odds of cessation (Public Health Service Guideline Update Panel, 2008). However, identifying

*Correspondence: Dr SR Goldberg, National Institute on Drug Abuse, Biomedical Research Center, 25I Bayview Boulevard, Baltimore, MD 21224, USA, Tel: + I 443740 2519, Fax: + I 4437402733 ,

E-mail: sgoldber@intra.nida.nih.gov

Received 24 October 2011; revised 31 January 2012; accepted 15 February 2012 new and effective treatment strategies is still critical given the enormity of the threat to public health.

Tobacco products such as cigarettes are essentially systems for the rapid delivery of nicotine to the brain. Nicotine produces rewarding effects through mesolimbic dopamine circuitry that is shared by other addictive drugs (Pontieri et al, 1996) and is concordant in humans and animals (Brody, 2006). In rodents, nicotine binds to acetylcholine receptors in the ventral tegmental area (VTA), enhancing the firing of dopamine neurons that project to the nucleus accumbens shell (Ikemoto, 2007; Mansvelder and McGehee, 2002). It has recently been discovered (Melis et al, 2008, 2010) that this nicotine-induced dopamine signaling is negatively modulated by $\alpha$-type peroxisome proliferator-activated receptors (PPAR $\alpha$ ).

$\operatorname{PPAR} \alpha$ are nuclear receptors that are strongly expressed in many tissues including specific areas of the brain (Moreno et al, 2004), have anti-inflammatory and neuroprotective 
effects (Pistis and Melis, 2010), and regulate lipid metabolism (O'Sullivan, 2007). We have shown that experimental drugs that activate PPAR $\alpha$ block nicotine-induced firing of dopamine neurons in the VTA and nicotine-induced elevations of extracellular dopamine levels in the nucleus accumbens shell of rats, and that they decrease nicotine-seeking behavior in rats and monkeys (Melis et al, 2008, 2010; Scherma et al, 2008; Forget et al, 2009; Luchicchi et al, 2010; Mascia et al, 2011). These preclinical findings suggest that $\operatorname{PPAR} \alpha$ could be an effective target for anti-smoking medications.

Although none of the treatment drugs in these previous studies have been approved for human use, there is a class of medications, the fibrates, that directly activate PPAR $\alpha$ and have been used for decades to prevent cardiovascular disease and other complications associated with abnormal lipid profiles (Jackevicius et al, 2011; Abourbih et al, 2009). If fibrate medications can block the addiction-related effects of nicotine in humans, the fact that they are already in clinical use could streamline their adoption as aids to smoking cessation. As smoking is associated with increased levels of triglycerides and diminished levels of high-density lipoprotein (Hata and Nakajima, 2000), fibrate medications might reduce smoking-related cardiovascular morbidity by improving lipid profiles and by removing the incentive to smoke.

The effects of fibrates on smoking have not been assessed in humans, nor have fibrates been tested in animal models of nicotine reward. Therefore, to set the stage for clinical trials, we assessed the effects of a representative fibrate drug, clofibrate, on: (1) acquisition of nicotine self-administration in naive rats; (2) ongoing nicotine self-administration in experienced rats and monkeys; (3) reinstatement of nicotine-seeking in monkeys, as a model of relapse; (4) food-maintained operant behavior in rats and monkeys; (5) discrimination of nicotine's subjective effects in rats; (6) nicotine-induced firing of dopamine cells in the VTA in rats; and (7) nicotine-induced dopamine elevations in the nucleus accumbens shell in rats.

\section{MATERIALS AND METHODS}

\section{Subjects}

Male Sprague-Dawley rats (Charles River Laboratories, Wilmington, MA, USA; Harlan-Nossan, Milan, Italy) weighing 300-350 g and male squirrel monkeys (Saimiri sciureus) weighing $0.9-1.1 \mathrm{~kg}$ were housed in individual cages in temperature- and humidity-controlled rooms. Electrophysiology experiments were conducted at the University of Cagliari in accordance with the European Economic Community Council Directive (86/609; DL27/01/92, no. 116). All other experiments were conducted at the Intramural Research Program of the National Institute on Drug Abuse in facilities fully accredited by the Association for Assessment and Accreditation of Laboratory Animal Care, in accordance with the guidelines of the National Research Council.

\section{Drugs}

Nicotine ((-)-nicotine hydrogen tartrate; Sigma, USA) was dissolved in saline solution ( $\mathrm{pH}$ adjusted to 7.0). Clofibrate
(Sigma) in liquid form was diluted with dimethylsulfoxide; vehicle-control injections consisted of $40 \%$ dimethylsulfoxide in saline. The PPAR- $\alpha$ antagonist MK886 (1-[(4-chlorophenyl) methyl]-3-[(1,1-dimethylethyl)thio]-a,a-dimethyl-5-(1-methylethyl)- $1 H$-indole-2-propanoic acid; Tocris, USA) was dissolved in $2-4 \%$ Tween-80, $4 \%$ dimethylsulfoxide, and sterile water. Rats were given intraperitoneal and subcutaneous treatments in a volume of $1 \mathrm{ml} / \mathrm{kg}$, and monkeys were given intramuscular treatments in a volume of $0.05-0.16 \mathrm{ml} / \mathrm{kg}$. The dose range for clofibrate was based on reports that $300 \mathrm{mg} / \mathrm{kg}$ per day intraperitoneally in rats is well tolerated and produces maximal effects on myocardial fatty-acid composition (Tian et al, 2010).

\section{Nicotine Self-Administration in Rats (General Procedure)}

General procedure and apparatus were described previously (Scherma et al, 2008; Panlilio et al, 2003). Self-administration sessions were $2 \mathrm{~h}$ long and began 7-10 days after catheterization. Initially, intravenous nicotine injections $(30 \mu \mathrm{g} / \mathrm{kg}$ per injection) were delivered under a one-response fixed-ratio schedule. Responses in the left nose-poke hole produced nicotine and pulsed the house light $(5 \mathrm{~Hz})$ for a $20 \mathrm{~s}$ timeout. Responses in the other, inactive hole had no scheduled effect.

\section{Acquisition of Nicotine Self-Administration in Rats}

The one-response fixed-ratio training schedule was used for 18 sessions. Starting 2 days before the first session, one group of rats received clofibrate $(300 \mathrm{mg} / \mathrm{kg}$, intraperitoneal, $100 \mathrm{~min}$ before session) daily and another group received vehicle daily. The acquisition criterion was $\geqslant 10$ self-injections per session for three consecutive sessions.

\section{Maintenance of Nicotine Self-Administration in Rats}

In a separate group of rats, the fixed-ratio requirement was increased to five responses per injection over 15-23 sessions and kept at this value for the remainder of the study. When a performance criterion ( $\geqslant 10$ nicotine injections per session for three consecutive sessions, with $<15 \%$ variation) was reached during baseline sessions on Monday and Tuesday, clofibrate treatments were tested Wednesday through Friday. Each dose (vehicle, 100, 200, or $300 \mathrm{mg} / \mathrm{kg}$, intraperitoneal, $100 \mathrm{~min}$ before session) was tested for three consecutive days, with the order of doses counterbalanced. In a separate experiment where two injections were given before each test session, the effects of clofibrate (vehicle or $100 \mathrm{mg} / \mathrm{kg}$, intraperitoneal) were tested in combination with the PPAR $\alpha$ antagonist MK886 (vehicle or $3 \mathrm{mg} / \mathrm{kg}$, intramuscular, $15 \mathrm{~min}$ before clofibrate). Owing to loss of catheter patency, some rats were not tested at all doses.

\section{Food Self-Administration in Rats}

Rats were trained with a food procedure that maintains rates and patterns of operant responding very similar to those of nicotine self-administration, with a brief phase of rapid self-administration at the beginning of the session and a slower, regularly spaced pattern for the remainder of the 
session; this pattern is engendered by emulating reinforcement dynamics thought to be responsible for the regulation of drug intake over time (for details see Panlilio et al, 2008). The training and testing procedures paralleled the nicotine maintenance procedure described above, except food pellets were delivered instead of nicotine, and availability of food was signaled by a light. Completion of each five-response fixed ratio was treated by the computer as a virtual injection of nicotine, and the rat's virtual nicotine level was calculated continuously based on a clearance half-life of $55 \mathrm{~min}$. The light was only presented when the virtual nicotine level was below $202 \mu \mathrm{g} / \mathrm{kg}$, the mean level (calculated using the procedure of Panlilio et al, 2003) at which rats self-administered nicotine in a previous study (Mascia et al, 2011). To assess potential interactions between nicotine and clofibrate, half the rats were treated with nicotine $(0.4 \mathrm{mg} / \mathrm{kg}$, subcutaneous, $10 \mathrm{~min}$ before session) and half with saline before every food self-administration session.

\section{Maintenance of Nicotine and Food Self-Administration in Monkeys}

General procedure and apparatus were described previously (Goldberg, 1973; Justinova et al, 2003). At the start of each 1 -h session, the houselight was extinguished and a green cuelight was presented. In the presence of the green light, 10 lever responses (10-response fixed ratio) produced a $0.2-\mathrm{s}$, $0.2-\mathrm{ml}, 30 \mu \mathrm{g} / \mathrm{kg}$ injection of nicotine, extinguished the green light, and illuminated an amber cuelight for $2 \mathrm{~s}$. Each injection was followed by a 60-s timeout, during which the chamber was dark and lever presses had no programmed effect. Food self-administration was studied in a separate group of monkeys using the same procedure, but delivering 190-mg food pellets instead of nicotine injections. The procedure for testing the effects of clofibrate under these self-administration maintenance conditions in monkeys was the same as in rats, except for clofibrate doses $(25,50$, and $100 \mathrm{mg} / \mathrm{kg}$ ), route of clofibrate administration (intramuscular), and the fact that vehicle was given before each baseline session in monkeys. The effects of clofibrate (100 mg/kg, intramuscular) were also tested in combination with the PPAR $\alpha$ antagonist MK886 ( $1 \mathrm{mg} / \mathrm{kg}$, intramuscular, 15 min before clofibrate).

\section{Nicotine-Induced Reinstatement of Nicotine-Seeking in Monkeys}

After completion of the nicotine self-administration maintenance study, extinction training and nicotine-induced reinstatement testing were conducted. The schedule of reinforcement during these extinction-training and reinstatement-test sessions was the same as under maintenance conditions, except intravenous saline was delivered instead of nicotine. When responding reached a low, stable level during extinction training ( $<10$ injections per session, with no obvious increasing or decreasing trend), a reinstatement test was conducted by giving a nicotine priming injection $(0.1 \mathrm{mg} / \mathrm{kg}$, intravenous, immediately before session) after treatment with clofibrate (vehicle or $100 \mathrm{mg} / \mathrm{kg}$, intramuscular, $100 \mathrm{~min}$ before the session) plus MK886 (vehicle, 1, or $3 \mathrm{mg} / \mathrm{kg}$, intramuscular, $115 \mathrm{~min}$ before the session).
Treatments were given in the home cage, and priming injections were given in the training chamber. Each test was performed for a single session, preceded by a baseline extinction session in which $0 \mathrm{mg} / \mathrm{kg}$ clofibrate (intramuscular vehicle) and $0 \mathrm{mg} / \mathrm{kg}$ nicotine (intravenous saline) were given before the session.

\section{Cue-Induced Reinstatement of Nicotine-Seeking in Monkeys}

After completion of the nicotine-induced reinstatement study, monkeys were returned to the nicotine maintenance condition for several weeks. Then, intravenous injections and injection-paired visual cues were discontinued (ie, the green cuelight remained on and the houselight remained off throughout the session) for three extinction sessions, during which response rates decreased to $<10$ completed ratios per session. Tests of cue-induced reinstatement were then conducted by presenting injection-paired visual cues (ie, green light off and amber light on, followed by timeout) and giving intravenous saline on the 10-response fixed-ratio schedule. Clofibrate $(100 \mathrm{mg} / \mathrm{kg}$, intramuscular), vehicle, or clofibrate plus MK886 (3 mg/kg, intramuscular) were given $100 \mathrm{~min}$ before each test session, with 2-3 extinction sessions before each test. One monkey was not tested owing to loss of catheter patency.

\section{Nicotine Discrimination in Rats}

General procedure and apparatus were described previously (Le Foll and Goldberg, 2004). Rats were trained under a discrete-trials schedule of food reinforcement (10 responses per pellet, 45-s timeout) in which responses on one lever produced food when an injection of nicotine $(0.4 \mathrm{mg} / \mathrm{kg}$, subcutaneous, $10 \mathrm{~min}$ before session) was given and responses on the other lever produced food when a saline injection was given. Sessions lasted for 20 pellets or $30 \mathrm{~min}$. Clofibrate (vehicle, 100,200 , or $300 \mathrm{mg} / \mathrm{kg}$, intraperitoneal, $100 \mathrm{~min}$ before session) and nicotine (vehicle, 0.03, 0.1, or $0.4 \mathrm{mg} / \mathrm{kg}$, subcutaneous, $10 \mathrm{~min}$ before session) were given before test sessions, up to two times per week. During test sessions, food was delivered whenever there were 10 consecutive non-timeout responses on either lever.

\section{Single-Unit Electrophysiology Recordings in Anesthetized Rats}

General procedure and apparatus were described previously (Melis et al, 2008). Single-unit activity of VTA neurons was recorded extracellularly with glass micropipettes filled with $2 \%$ pontamine sky blue dissolved in $0.5 \mathrm{M}$ sodium acetate (impedance $2-5 \mathrm{M} \Omega$ ). One cell was recorded per rat. Single units were isolated and identified according to previously published criteria (Grace and Bunney, 1984; Ungless et al, 2004). All neurons were antidromically identified as projecting to the nucleus accumbens shell by antidromic spikes elicited by stimulation of the shell of the nucleus accumbens. An antidromic response was defined as the ability of evoked spikes to follow stimulation frequencies of $>250 \mathrm{~Hz}$, displaying constant latency and collision with spontaneously occurring spikes (Lipski, 1981). Nicotine $(0.2 \mathrm{mg} / \mathrm{kg}$, intravenous) was administered after 5-10 min 
of baseline recording. Clofibrate (vehicle, 200 , or $300 \mathrm{mg} / \mathrm{kg}$, intraperitoneal) was injected $\sim 30 \mathrm{~min}$ before the start of recordings, and MK886 (3 or $10 \mathrm{mg} / \mathrm{kg}$, intraperitoneal) was injected $15 \mathrm{~min}$ before clofibrate. Baseline firing rates did not differ between conditions (mean $\mathrm{Hz} \pm \mathrm{SEM}-$ controls: $3.4 \pm 0.4$; clofibrate $200 \mathrm{mg} / \mathrm{kg}: 4.2 \pm 0.3$; clofibrate $300 \mathrm{mg} / \mathrm{kg}: 4.1 \pm 0.6)$.

\section{In Vivo Microdialysis in Freely Moving Rats}

General procedure and apparatus were described previously (Solinas et al, 2007). Rats (separate from the rats tested in the electrophysiology study) were surgically implanted with a concentric dialysis probe aimed at the shell of the nucleus accumbens (anterior +2.0 and lateral 1.1 from bregma, vertical -8.0 from dura) (Paxinos and Watson, 2007). Experiments were performed on freely moving rats $20-24 \mathrm{~h}$ after implantation. Ringer's solution $(147.0 \mathrm{mM} \mathrm{NaCl}, 2.2 \mathrm{mM}$ $\mathrm{CaCl}_{2}, 4.0 \mathrm{mM} \mathrm{KCl}$ ) was delivered at a constant flow rate of $0.5 \mu \mathrm{l} / \mathrm{min}$. Collection of dialysate samples $(10 \mu \mathrm{l}$ per sample) started after $90 \mathrm{~min}$, with samples collected every $20 \mathrm{~min}$ and immediately analyzed by a high-performance liquid chromatography system coupled to electrochemical detection to quantify dopamine. Rats were treated only after stable dopamine values ( $<10 \%$ variability) were obtained for at least three consecutive samples. Probe location in the nucleus accumbens shell was determined histologically after each experiment, and only data from rats with correct probe placement were analyzed. Clofibrate (vehicle or $300 \mathrm{mg} / \mathrm{kg}$, intraperitoneal) was given $60 \mathrm{~min}$ before nicotine $(0.4 \mathrm{mg} / \mathrm{kg}$, intraperitoneal), and MK886 (vehicle or $3 \mathrm{mg} / \mathrm{kg}$, intraperitoneally) was given $20 \mathrm{~min}$ before clofibrate. Basal levels of dopamine in dialysates, expressed as mean fmoles per $10 \mu \mathrm{l}$ sample $\pm \mathrm{SEM}$, did not differ between groups before injections (vehicle + vehicle + nicotine: $31.9 \pm 2.74$; vehicle + clofibrate + nicotine: $39.72 \pm 4.7$; vehicle + clofibrate + saline: $31.47 \pm 3.1$; MK886 + clofibrate + nicotine: $64.40 \pm 13.5$ ).

\section{Data Analysis}

Behavioral and microdialysis data were analyzed using Proc Mixed (SAS Institute, Cary, NC, USA) with Tukey-Kramer comparisons. Acquisition data were combined into twosession blocks; the independent variables were treatment group (vehicle $v s$ clofibrate), hole (active $v s$ inactive), and block. For maintenance experiments, the mean for the 3 days of each test were compared with the mean from the previous two baseline sessions; the independent variables were treatment (dose) and session (baseline $v s$ treatment). For illustration of effects over consecutive sessions, additional analyses were performed using session as a factor and comparing each test session to the mean of the two preceding baseline sessions. Reinstatement data were analyzed using a one-way repeated measures design, with baseline data combined across sessions. Nicotine discrimination data were analyzed separately for percentage of responses on the nicotine-appropriate lever and for response rate, with nicotine dose and clofibrate dose as factors. Dopamine levels from the microdialysis procedure were expressed as a percentage of basal level and analyzed with treatment and time as factors; area under the curve was calculated for the $120 \mathrm{~min}$ following nicotine injection, expressed as a percentage of the vehicle + vehicle + nicotine condition, and analyzed with a one-way model. Electrophysiology data were analyzed using analysis of variance with StudentNewman-Keuls comparisons. Family-wise confidence levels of 0.05 were used for all comparisons.

\section{RESULTS}

\section{Nicotine was Not Rewarding in Naive Rats Treated with Clofibrate}

Acquisition of nicotine self-administration was studied in naive rats to assess clofibrate's effects on the rewarding properties of nicotine. Six out of nine rats that were treated daily with vehicle learned to self-administer nicotine by responding in the active nose-poke hole, but none of the nine rats that were treated daily with clofibrate acquired this behavior. Response rates in the active hole were significantly higher in the vehicle group than in the clofibrate group, and only vehicle-treated rats responded significantly more in the active hole than in the inactive hole (Figure 1; group $\times$ hole interaction, $\mathrm{F}(1,16)=14.69, p<0.002)$.

\section{Clofibrate Decreased Ongoing Nicotine Self- Administration in Experienced Rats and Monkeys}

The effects of clofibrate were studied in nicotine-experienced animals to assess the potential of fibrate medications for inducing and maintaining smoking cessation. Clofibrate dose-dependently reduced the number of nicotine injections in rats (Figure 2a; treatment $\times$ session interaction, $\mathrm{F}(3,12)=9.49, p<0.002$ ) and monkeys (Figure 3a; treatment $\times$ session interaction, $\mathrm{F}(4,1)=15.07, p<0.0002)$ that

\section{Acquisition of Nicotine Self-Administration (Rats)}

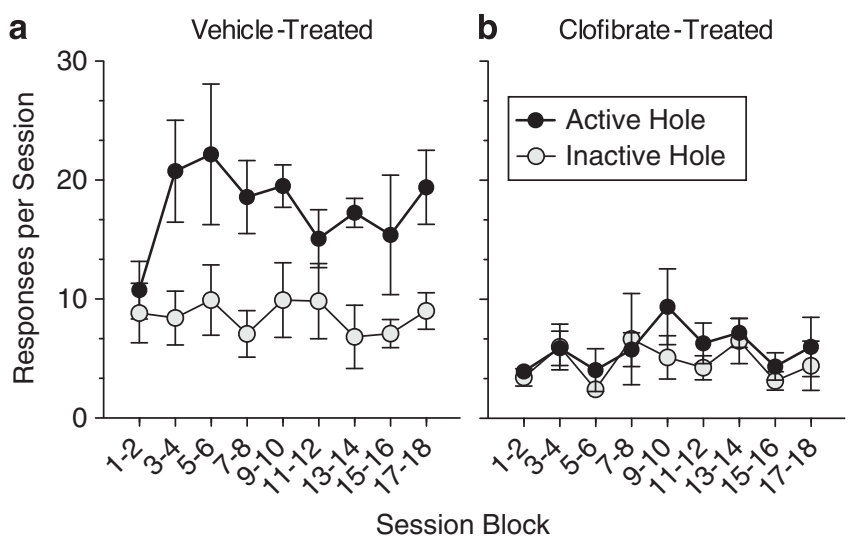

Figure I Clofibrate prevented the acquisition of nicotine self-administration in nicotine-naive rats. Rats treated daily with vehicle (a) learned to self-administer nicotine $(30 \mu \mathrm{g} / \mathrm{kg}$ nicotine per injection) by performing a nose-poke response, but rats treated daily with $300 \mathrm{mg} / \mathrm{kg}$ clofibrate (b) failed to acquire this behavior. Clofibrate-treated rats responded in the active nose-poke hole at a significantly lower rate than vehicle-treated rats, and only vehicle-treated rats responded significantly more in the active hole than in the inactive hole (which did not produce nicotine). By the end of training, 6 out of 9 vehicle-treated rats and 0 out of 9 clofibrate-treated rats met the acquisition criterion ( $\geqslant 10$ injections per session for 3 consecutive sessions). One active-hole response was required for each nicotine injection, and sessions lasted $2 \mathrm{~h}$. All data were presented as mean \pm SEM. 
had already established a habitual level of nicotine use. When clofibrate treatment was discontinued, nicotine selfadministration resumed (Figures $2 \mathrm{~b}$ and $3 \mathrm{~b}$ ). Clofibrate's effects on nicotine self-administration in rats (Figure 2c; treatment $\times$ session interaction, $\mathrm{F}(3,19)=3.68, p<0.03)$ and monkeys (Figure 3a) were due to its actions at PPAR $\alpha$, as the effects were blocked by the PPAR $\alpha$ antagonist MK886, which had no effect when given alone.

\section{Clofibrate Did Not Disrupt Food Self-Administration in Rats or Monkeys}

Under baseline conditions, rates of food self-administration in rats (Figure 2d) and monkeys (Figure 3c) were comparable to rates of nicotine self-administration (Figures $2 \mathrm{a}$ and $3 \mathrm{a}$, respectively). However, unlike nicotine selfadministration, food self-administration was not substantially affected by treatment with clofibrate in monkeys or rats. Food self-administration was also not affected by the combination of nicotine and clofibrate (Figure $2 \mathrm{~d}$, right panel). In rats, the treatment $\times$ session interaction was significant $(\mathrm{F}(3,30)=3.96, p<0.02)$, but none of the treatment $\times$ session paired comparisons were significant (all $p$ 's $>0.18$ ). In monkeys, all main effects and interactions were nonsignificant. These results indicate that clofibrate's effects on nicotine self-administration do not represent a nonspecific suppression of operant behavior.

\section{Clofibrate Counteracted the Relapse-Like Behavior Induced by Re-Exposure to Nicotine}

In monkeys that had extensive experience self-administering nicotine, responding dropped to a low level when abstinence was imposed by substituting saline injections for nicotine. Re-exposure to nicotine reinstated the nicotineseeking response, but this reinstatement was significantly reduced by treatment with $100 \mathrm{mg} / \mathrm{kg}$ clofibrate (Figure 4a; effect of treatment $F(4,12)=22.46, p<0.0001)$. This effect of clofibrate was dose-dependently reversed by the PPAR $\alpha$ antagonist MK886 (Figure 4a).

\section{Clofibrate Counteracted the Relapse-Like Behavior Induced by Nicotine-Related Cues}

Monkeys' response rates dropped to a low level when nicotine and the presentation of cues signaling the delivery of nicotine were not presented. Nicotine-seeking was robustly reinstated when cue presentation was reinstituted, but this effect was significantly decreased by treatment with clofibrate (Figure $4 \mathrm{~b}$; effect of treatment $\mathrm{F}(3,6)=173.4, p<0.0001$ ). This effect of clofibrate was reversed by MK886 $(3 \mathrm{mg} / \mathrm{kg})$.

\section{Clofibrate-Treated Rats Could Still Detect Interoceptive Effects of Nicotine}

In the nicotine discrimination procedure, lever choice was highly dependent on the dose of nicotine (Figure 5a; main
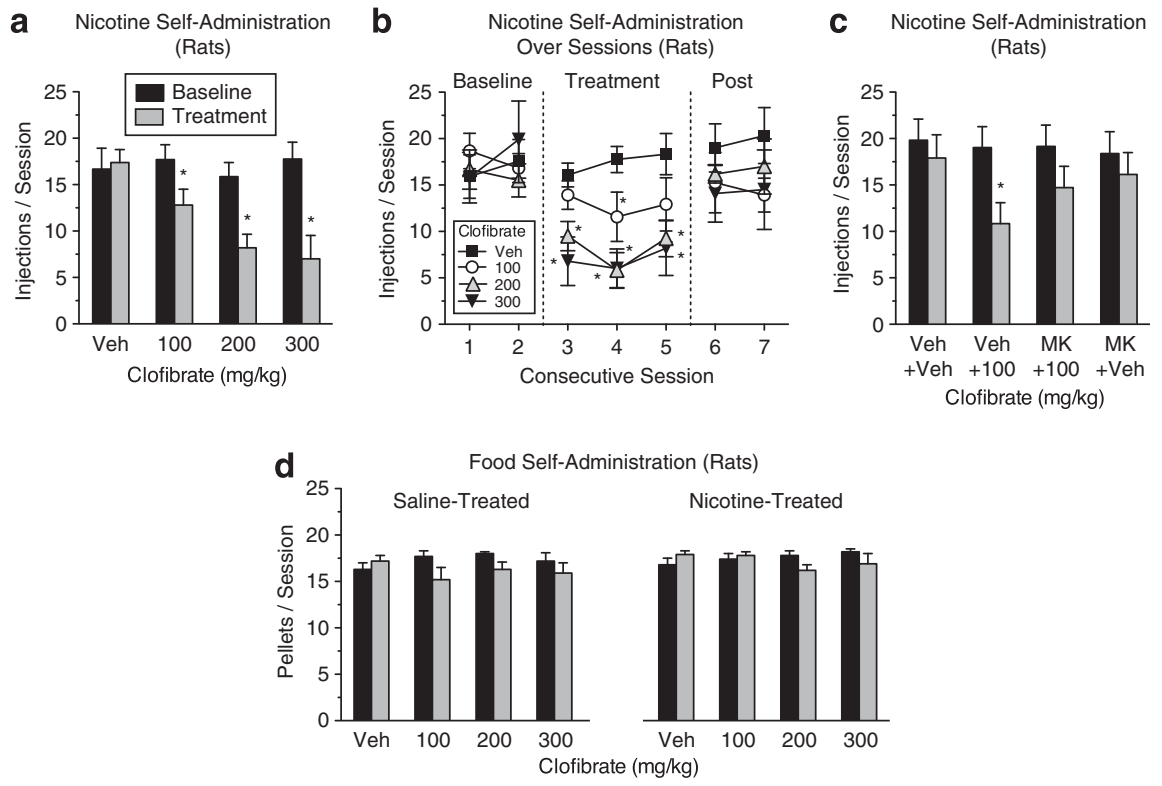

Figure 2 Clofibrate decreased nicotine self-administration in rats that had established a stable baseline of nicotine intake, but it did not alter food selfadministration under a procedure in which baseline rates and patterns of responding were comparable to those of nicotine self-administration. Each dose of clofibrate was tested for three consecutive days. (a) Nicotine injection rates averaged across the 3 days of treatment and across the two preceding baseline days. (b) Nicotine injection rates on each day of testing, the two preceding baseline days, and the two sessions after treatment was discontinued ('Post'). The two higher doses of clofibrate decreased nicotine intake during each day of testing. $n=13,8,7$, and 5, respectively, for the vehicle ('Veh'), I00, 200, and $300 \mathrm{mg} / \mathrm{kg}$ conditions. (c) Nicotine injection rates averaged across the 3 days of treatment and across the two preceding baseline days for rats given two injections (a pretreatment injection of the PPAR $\alpha$ antagonist MK886 ('MK'; 3 mg/kg) or vehicle and a treatment injection of clofibrate (I00 mg/ $/ \mathrm{kg}$ ) or vehicle) before each test session. Clofibrate alone significantly decreased nicotine self-administration, but this effect was blocked by MK886; $n=7,11$, II, and 9 , respectively, for the 'Veh + Veh', 'Veh + 100', 'MK + 100', and 'MK + Veh' conditions. (d) Rates of food self-administration averaged across the 3 days of treatment and across the two preceding baseline days. Rats received subcutaneous injections of nicotine $(n=6)$ or saline $(n=6)$ before every session. Clofibrate, nicotine, and their combination did not significantly alter food self-administration. In all panels, five responses were required for each nicotine injection or food pellet, and sessions lasted $2 \mathrm{~h}$. *Significant difference from baseline. All data were presented as mean \pm SEM. 

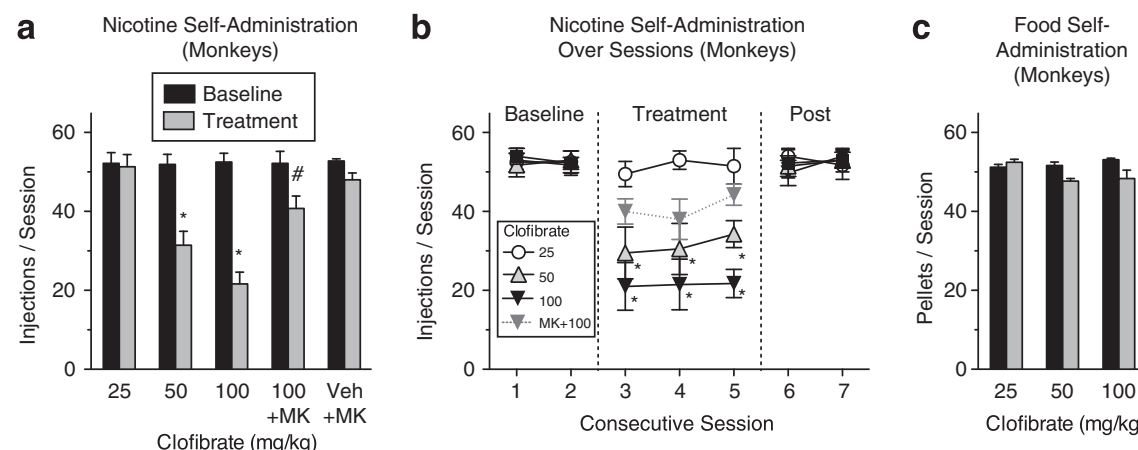

Figure 3 Clofibrate decreased nicotine self-administration, but not food self-administration, in squirrel monkeys. (a) Nicotine injection rates averaged across the 3 days of treatment and across the two preceding baseline days. (b) Nicotine injection rates on each day of testing, the two preceding baseline days, and the two sessions after treatment was discontinued ('Post'). The two higher doses of clofibrate decreased nicotine intake during each day of testing. The PPAR $\alpha$ antagonist MK886 ('MK'; I mg/ $\mathrm{kg}$ ) blocked the effect of clofibrate $(100 \mathrm{mg} / \mathrm{kg}$ ), indicating that clofibrate's effects on nicotine intake were due to its actions at $\alpha$-type peroxisome proliferator-activated receptors (PPAR $\alpha$ ). (c) Clofibrate did not significantly affect food-rewarded behavior in monkeys tested under conditions that paralleled the nicotine self-administration procedure; $n=4$ for nicotine self-administration and $n=3$ for food. Clofibrate's vehicle was given before each baseline session. In all conditions, 10 lever responses were required for each nicotine injection or food pellet, and sessions lasted I h. *Significant decrease compared with baseline. " Significant increase compared with $100 \mathrm{mg} / \mathrm{kg}$ clofibrate condition. All data were presented as mean \pm SEM.
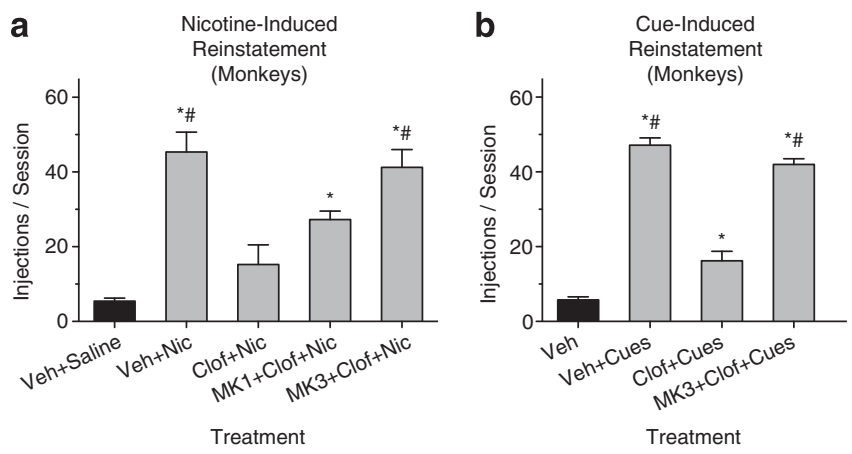

Figure 4 Clofibrate had a protective effect in models of nicotine- and cue-induced relapse in squirrel monkeys. (a) Nicotine-induced reinstatement. A baseline of nicotine abstinence and low rates of nicotine seeking was arranged by substituting saline for nicotine in the intravenous selfadministration procedure. During test sessions, a priming injection of nicotine was given automatically before the session. When monkeys were given only clofibrate's vehicle before the nicotine priming injection ('Veh + Nic' condition), the nicotine prime significantly reinstated nicotine-seeking behavior. However, when monkeys were given $100 \mathrm{mg} / \mathrm{kg}$ clofibrate $100 \mathrm{~min}$ before the priming injection ('Clof + Nic' condition), nicotineseeking was not reinstated. MK886 reversed this effect of clofibrate partially at a dose of I mg/kg ('MKI + Clof + Nic' condition) and fully at $3 \mathrm{mg} / \mathrm{kg}$ ('MK3 + Clof + Nic' condition). On the baseline day before each test session, monkeys were given clofibrate's vehicle followed by a saline injection instead of a nicotine prime; data from these sessions were combined across days ('Veh + Saline' condition). *Significant difference from 'Veh + Saline' condition. "\#ignificant difference from 'Clof + Nic' condition. (b) Cue-induced reinstatement. A baseline of nicotine abstinence and low rates of nicotine seeking was arranged by discontinuing intravenous injections and the presentation of visual cues ('Veh' condition). During test sessions, cue presentation was reinstituted, and responding produced intravenous saline injections. The cues significantly reinstated nicotine seeking when monkeys were treated with vehicle ('Veh + Cues' condition), but this effect was significantly blocked by treatment with 100 mg/kg clofibrate ('Clof + Cues' condition). *Significant difference from 'Veh' condition. "\#Significant difference from 'Clof + Cues' condition; $n=4$ for nicotine-induced reinstatement and $n=3$ for cue-induced reinstatement. In all, 10 lever responses were required for each saline injection, and sessions lasted I h. Data for 'Veh' (black bar) in panel b represent number of responses divided by 10 , as no injections or timeouts were given in this condition. All data were presented as mean \pm SEM. effect of nicotine, $\mathrm{F}(3,33)=129.88, p<0.0001)$, and clofibrate did not significantly alter this discrimination. Nicotine, clofibrate, and their combination did not significantly affect the rate of food-rewarded responding in this procedure (Figure 5b; all $p$ 's $>0.38$ ), consistent with clofibrate selectively blocking the rewarding effects of nicotine rather than suppressing operant behavior in general.

\section{Clofibrate Blocked Nicotine-Induced Firing of Dopamine Cells in the VTA}

Intravenous injection of nicotine enhanced the firing rate of VTA dopamine neurons that project to the nucleus accumbens shell (Figure 6a and d; effect of nicotine, $F(4,32)=$ 4.99, $p<0.01)$. Clofibrate alone did not alter the baseline rate of spontaneous firing, but it significantly blocked nicotine-induced increases in firing (Figure $6 \mathrm{~b}$ and d; effect of clofibrate, $\mathrm{F}(1,44)=5.69, p<0.05)$. The PPAR $\alpha$ antagonist MK886 (10 mg/kg) reversed the effects of clofibrate, restoring nicotine's ability to increase firing (Figure 6c and d; MK886 + clofibrate $v s$ clofibrate, $\mathrm{F}(1,28)=6.03$, $p<0.05)$.

\section{Clofibrate Blocked Nicotine-Induced Elevations of Dopamine in the Nucleus Accumbens Shell}

Nicotine $(0.4 \mathrm{mg} / \mathrm{kg}$, subcutaneous) increased extracellular dopamine levels in the nucleus accumbens shell by about $90 \%$ (Figure 7a; treatment $\times$ time interaction, $\mathrm{F}(36,202)=$ $3.08, p<0.0001)$. Clofibrate significantly blocked this effect of nicotine, reducing the area under the curve by about $40 \%$ (Figure 7b; effect of treatment, $\mathrm{F}(3,17)=14.73, p<0.0001$ ). MK886 reversed this effect of clofibrate (Figure $7 a$ and $b$ ). Clofibrate did not alter dopamine levels when given alone (ie, without nicotine; Figure $7 \mathrm{a}$ and $\mathrm{b}$ ), and this dose of MK886 was shown earlier to have no effect when given alone in this procedure (Mascia et al, 2011). 
a

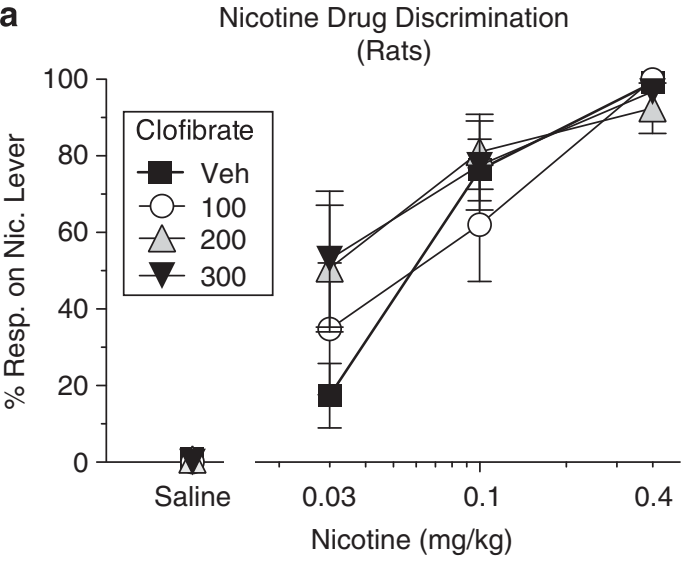

b

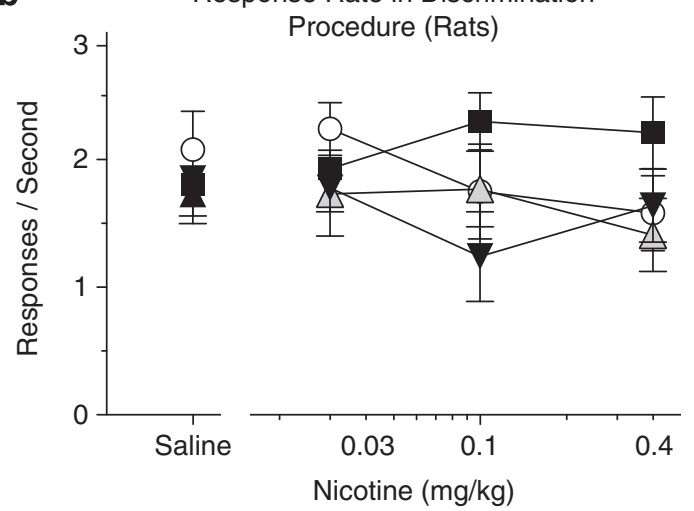

Figure 5 (a) Clofibrate did not alter rat's ability to detect interoceptive effects of nicotine in the nicotine discrimination procedure. During training, responding on one lever produced food pellets on days when rats were given a subcutaneous nicotine injection $(0.4 \mathrm{mg} / \mathrm{kg})$, and responding on another lever produced food pellets on days when they were given a saline injection. When rats were given clofibrate's vehicle ('Veh') and tested with various doses of nicotine, the percentage of responses on the nicotineappropriate lever ('\% Resp. on Nic. Lever') was a monotonically increasing function of dose. Treatment with clofibrate did not significantly alter this curve. (b) Rates of food-reinforced responding in the nicotine discrimination procedure. Clofibrate, nicotine, and their combination did not significantly alter the rate of responding during the same test sessions depicted in panel a. In all, 10 responses were required for each food pellet; $n=12$. All data were presented as mean \pm SEM.

\section{DISCUSSION}

Clofibrate blocked the rewarding effects of nicotine in naive animals, decreased nicotine use in nicotine-experienced animals, counteracted the relapse-like effects induced by re-exposure to nicotine or nicotine-associated cues, and blocked nicotine's reward-related effects on dopamine signaling. The effects of clofibrate were selective for nicotine (having no effect on food-maintained operant behavior) and were mediated by PPAR $\alpha$, as demonstrated by reversal with the PPAR $\alpha$ antagonist MK886. These findings extend our earlier findings with experimental drugs that activate $\operatorname{PPAR} \alpha$ and suggest that fibrate medications could be useful for treating tobacco dependence.

$\operatorname{PPAR} \alpha$ activation promotes phosphorylation of $\beta 2$ nicotinic acetylcholine receptors in the VTA by stimulating tyrosine kinases that can lead to the downregulation of nicotinic receptors (Melis et al, 2008, 2010). This is

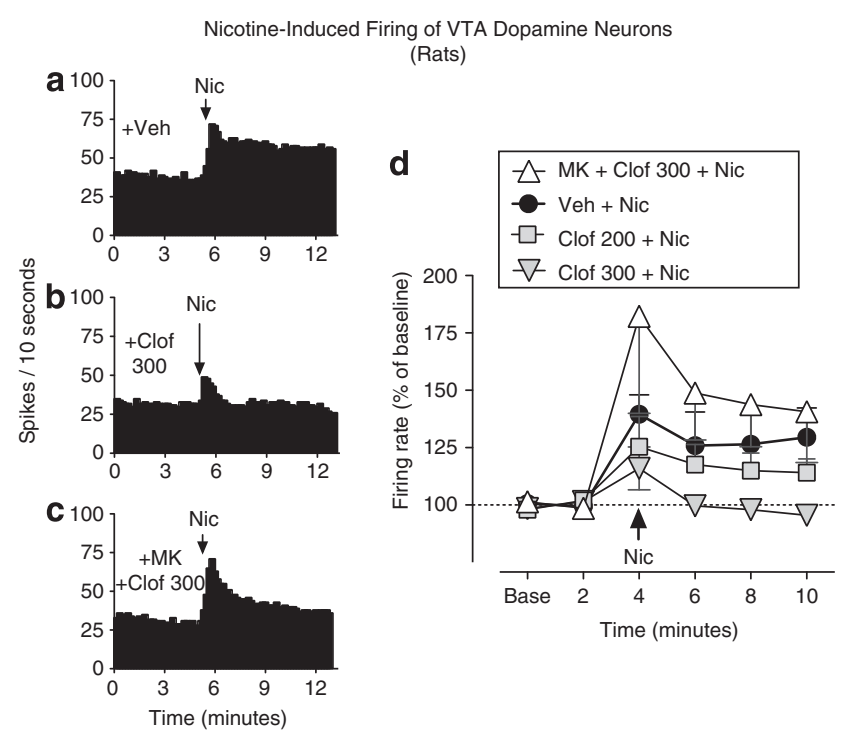

Figure 6 Clofibrate blocked the effects of nicotine on firing of ventral tegmental area (VTA) dopamine cells. In single-cell electrophysiology experiments in anesthetized rats, nicotine significantly increased the firing rate of these cells, which were antidromically identified as projecting to the nucleus accumbens shell. This effect of nicotine was partially blocked by $200 \mathrm{mg} / \mathrm{kg}$ clofibrate and completely blocked by $300 \mathrm{mg} / \mathrm{kg}$ clofibrate. Administration of the PPAR- $\alpha$ antagonist MK886 ('MK'; $10 \mathrm{mg} / \mathrm{kg}$, intraperitoneally) before clofibrate prevented clofibrate from altering the effects of nicotine. Histograms show firing of representative single cells over time in rats pretreated with (a) vehicle ('Veh'), (b) $300 \mathrm{mg} / \mathrm{kg}$ clofibrate ('Clof 300'), or (c) 10 mg/kg MK886 plus 300 mg/kg clofibrate ('MK + Clof $\left.300^{\prime}\right)$. (d) Mean ( \pm SEM) firing rates over time for the same three treatment conditions as panels a-c, and also after treatment with $200 \mathrm{mg} / \mathrm{kg}$ clofibrate. Arrows indicate time of nicotine ('Nic') administration; $n=9$ for vehicle, $n=7$ for both doses of clofibrate, and $n=5$ for MK886 + clofibrate.

presumably the mechanism by which $\operatorname{PPAR} \alpha$ activation blocks the dopaminergic effects of nicotine in the VTA and nucleus accumbens shell, which are believed to provide the primary basis for nicotine reward (Gotti et al, 2010; Corrigall et al, 1994; Lecca et al, 2006). This nicotineinduced dopaminergic signaling, and indeed the rewarding effects of nicotine in behavioral procedures, have been shown to be blocked by experimental drugs that activate $\operatorname{PPAR} \alpha$ directly (ie, the synthetic agonist WY14643, the endogenous ligands oleoylethanolamine and palmitoylethanolamide, and the longer-acting oleoylethanolamine derivative methyl oleoylethanolamine; Melis et al, 2008, 2010; Mascia et al, 2011) or indirectly (ie, the fatty-acid amide hydrolase inhibitor URB597; Melis et al, 2008; Scherma et al, 2008; Forget et al, 2009; Luchicchi et al, 2010). The electrophysiology, microdialysis, and behavioral experiments of this study extend these findings to the fibrate class of medications.

Nicotine increases the firing rate of dopamine neurons that project to the nucleus accumbens shell, stimulating action potential-evoked release of dopamine. However, nicotine can also evoke dopamine release from directly within the shell (Kleijn et al, 2011). In both this study with clofibrate and our earlier study with the direct PPAR $\alpha$ agonists WY14643 and methyl oleoylethanolamine (Mascia et al, 2011), PPAR $\alpha$ activation completely blocked nicotine's effects on dopamine cell firing in the VTA, but only partially 
a
Nicotine-Induced Dopamine Overflow in Nucleus Accumbens Shell (Rats)

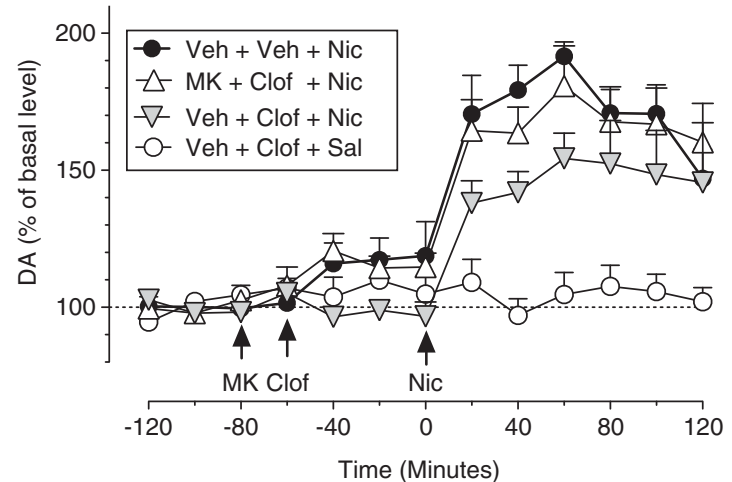

b

Nicotine-Induced Dopamine

Overflow, as AUC (Rats)

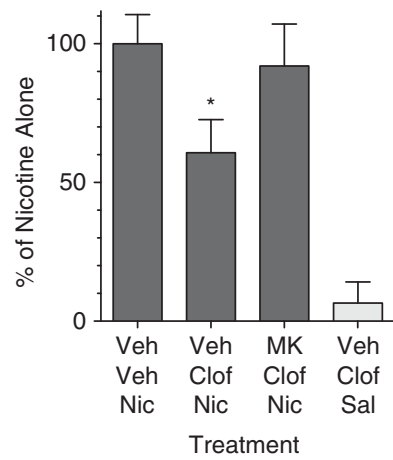

Figure 7 Clofibrate blocked nicotine-induced elevations of extracellular dopamine in the nucleus accumbens shell. Microdialysis was performed in awake, freely moving rats. Nicotine ('Nic'; $0.4 \mathrm{mg} / \mathrm{kg}$, intravenously) significantly increased dopamine ('DA') levels, but this effect was significantly blocked by treatment with $300 \mathrm{mg} / \mathrm{kg}$ clofibrate ('Clof'). Administration of the PPAR- $\alpha$ antagonist MK886 ('MK'; $3 \mathrm{mg} / \mathrm{kg}$, intraperitoneally) 20 min before clofibrate reversed the effects of clofibrate. (a) Dopamine levels (expressed as a percentage of basal level) over time in rats treated with MK886 or its vehicle, followed by clofibrate ('Clof') or its vehicle, and finally by nicotine ('Nic') or saline ('Sal'). Arrows indicate times of drug or vehicle ('Veh') administration. (b) Dopamine levels for the same four conditions, expressed as area under the curve ('AUC', relative to the mean level in the 'Veh + Veh + Nic' condition) over the $2 \mathrm{~h}$ following nicotine or saline injection. *Significant decrease compared to 'Veh + Veh + Nic' condition; $n=5$ for all conditions except MK886 ( $n=6)$. All data were presented as mean \pm SEM.

blocked nicotine-induced elevations of extracellular dopamine levels in the accumbens shell. These results suggest that $\operatorname{PPAR} \alpha$ activation does not prevent dopamine release that is directly evoked by nicotine within the accumbens shell, possibly because PPAR $\alpha$ are nuclear receptors, located in the cell body but not in the terminals (Moreno et al, 2004). In addition, previous work has shown that nicotineevoked dopamine release in the accumbens is relatively insensitive to blockade of nicotinic receptors within the area (Nisell et al, 1994). Thus, clofibrate does not completely block nicotine's effects on dopamine signaling, but the level of blockade it does produce is substantial and consistent with the observed reductions in nicotine self-administration and reinstatement.

Although a fibrate medication would not be prescribed to prevent the initial development of tobacco use, the finding that clofibrate (like enhancement of endogenous PPAR $\alpha$ ligands; Scherma et al, 2008) can block the acquisition of nicotine self-administration in naive rats indicates that PPAR $\alpha$ activation counteracts the primary reinforcing effects of nicotine. The finding that clofibrate decreases ongoing nicotine self-administration in experienced animals suggests that blocking nicotine's reinforcing effects with a fibrate might reduce smoking or help induce abstinence in smokers with established habits. This is consistent with the literature indicating that with continued experience drug use becomes more habitual and less susceptible to change (Everitt and Robbins, 2005), but that reducing the rewarding effects of nicotine can decrease smoking in habitual users (Rose, 2008).

Abstinence from smoking is easier to achieve than to maintain. For example, among those who quit for 4 weeks, about $75 \%$ relapse within a year (Ferguson et al, 2005). Therefore, relapse is considered the most significant obstacle to smoking cessation. Two major factors that contribute to relapse are nicotine re-exposure (Chornock et al, 1992) and smoking-related environmental cues (Shiffman, 1982). It is especially promising that in this study clofibrate had a protective effect against both nicotine- and cue-induced reinstatement. Clofibrate's ability to counteract nicotinerelated cues is consistent with the findings that PPAR $\alpha$ agonists downregulate nicotinic receptors (Melis et al, 2010) and that cue-induced nicotine-seeking depends upon the action of acetylcholine at nicotinic receptors (Liu et al, 2007). If clofibrate can indeed counteract the effects of smoking-related cues, this could make it a valuable adjunct or alternative to bupropion, varenicline, and nicotine patch therapies, which do not appear to protect against cueinduced nicotine craving in humans (Ferguson and Shiffman, 2009) or cue-induced nicotine-seeking in rats (Wouda et al, 2011; Liu et al, 2008).

Nicotine's interoceptive effects are known to involve a number of neurotransmitters, but dopamine blockade does not prevent detection of nicotine in rats (Smith and Stolerman, 2009). Moreover, earlier studies indicate that nicotine's interoceptive effects do not correspond well with its rewarding or reinstatement-inducing effects (see discussion by Mascia et al, 2011). Thus, it is not surprising that rats treated with clofibrate are still capable of discriminating between injections of nicotine and saline, even though nicotine's reward-related dopaminergic effects are blocked. It is not clear whether nicotine's non-dopaminergic effects contribute to tobacco dependence, but the interoceptive effects spared by PPAR $\alpha$ activation in rats might be related to the aversive interoceptive effects of nicotine reported by humans (Harvey et al, 2004).

The finding that clofibrate has promising effects in animal models of nicotine reward and relapse suggests that other fibrate drugs would also be effective. Clofibrate was chosen to represent this class of medications in this study, but a number of fibrate medications are in clinical use, comprising almost $1 \%$ of all prescriptions in the United States (Jackevicius et al, 2011). All of these drugs (fenofibrate, gemfibrozil, bezafibrate, and ciprofibrate) selectively 
activate $\operatorname{PPAR} \alpha$. Unfortunately, epidemiological studies have not been conducted to assess the effects of fibrates on smoking, and clinical efficacy and ideal dosing parameters cannot be fully assessed using animal models. Therefore, further studies should be conducted by administering fibrates in clinical trials focused on smoking cessation and relapse.

Fibrates are efficacious for the treatment of primary hypercholesterolemia, mixed dyslipidemia, and hypertriglyceridemia, and they are typically given along with statins or as a monotherapy in patients who are refractory or intolerant to statins (Abourbih et al, 2009). Like all medications, fibrates can have side effects, and the potential dual benefit of reduced smoking and improved lipid profile will have to be weighed against the potential for adverse effects. In double-blind clinical trials with fenofibrate, the most widely prescribed fibrate, adverse events led to discontinuation of treatment in $5 \%$ of patients, compared with $3 \%$ of those treated with placebo; the most common side effect involved changes in liver enzymes, so liver enzyme and lipid profiles are monitored periodically to ensure safety and optimize dose (Abbott Laboratories, 2011).

\section{Conclusion}

Smoking is highly addictive and increases the risk of cardiovascular disease and mortality. Fibrate medications might reduce this risk in two ways, by promoting smoking cessation and by improving cardiovascular health. Medication development is an expensive and lengthy process, and the fact that fibrates are already approved for human use is a significant advantage that could expedite clinical trials and subsequent implementation of fibrates as a treatment for tobacco dependence, especially in smokers with abnormal lipid profiles.

\section{ACKNOWLEDGEMENTS}

This study was supported by the Intramural Research Program of the National Institute on Drug Abuse, National Institutes of Health, Department of Health and Human Services; National Institute on Drug Abuse Residential Research Support Services Contract No. N01 DA59909 (Kelly PI); the Regione Autonoma della Sardegna (Italy), Assessorato alla Programmazione; and the Division of Geriatric Medicine and Gerontology, Johns Hopkins University School of Medicine, Baltimore.

\section{DISCLOSURE}

The authors declare no conflict of interest.

\section{REFERENCES}

Abbott Laboratories (2011). Product Information: Tricor ${ }^{\mathrm{TM}}$ Fenofibrate Tablets.

Abourbih S, Filion KB, Joseph L, Schiffrin EL, Rinfret S, Poirier P et al (2009). Effect of fibrates on lipid profiles and cardiovascular outcomes: a systematic review. Am J Med 962: e1-e8.

Brody AL (2006). Functional brain imaging of tobacco use and dependence. J Psychiatr Res 40: 404-418.
Centers for Disease Control and Prevention (2008). Smokingattributable mortality, years of potential life lost, and productivity losses - United States, 2000-2004. Morb Mortal Wkly Rep 57: 1226-1228.

Chornock WM, Stitzer ML, Gross J, Leischow S (1992). Experimental model of smoking re-exposure: effects on relapse. Psychopharmacology 108: 495-500.

Corrigall WA, Coen KM, Adamson KL (1994). Self-administered nicotine activates the mesolimbic dopamine system through the ventral tegmental area. Brain Res 653: 278-284.

Critchley JA, Capewell S (2003). Mortality risk reduction associated with smoking cessation in patients with coronary heart disease: a systematic review. JAMA 290: 86-97.

Everitt BJ, Robbins TW (2005). Neural systems of reinforcement for drug addiction: from actions to habits to compulsion. Nat Neurosci 8: 1481-1489.

Ferguson J, Bauld L, Chesterman J, Judge K (2005). The English smoking treatment services: one-year outcomes. Addiction 100(Suppl 2): 59-69.

Ferguson SG, Shiffman S (2009). The relevance and treatment of cue-induced cravings in tobacco dependence. J Subst Abuse Treat 36: 235-243.

Forget B, Coen KM, Le Foll B (2009). Inhibition of fatty acid amide hydrolase reduces reinstatement of nicotine seeking but not break point for nicotine self-administration-comparison with CB(1) receptor blockade. Psychopharmacology 205: 613-624.

Goldberg SR (1973). Comparable behavior maintained under fixed-ratio and second-order schedules of food presentation, cocaine injection or $\mathrm{d}$-amphetamine injection in the squirrel monkey. J Pharmacol Exp Ther 186: 18-30.

Gotti C, Guiducci S, Tedesco V, Corbioli S, Zanetti L, Moretti M et al (2010). Nicotinic acetylcholine receptors in the mesolimbic pathway: primary role of ventral tegmental area alpha6beta $2^{*}$ receptors in mediating systemic nicotine effects on dopamine release, locomotion, and reinforcement. J Neurosci 30: 5311-5325.

Grace AA, Bunney BS (1984). The control of firing pattern in nigral dopamine neurons: burst firing. J Neurosci 4: 2877-2890.

Harvey DM, Yasar S, Heishman SJ, Panlilio LV, Henningfield JE, Goldberg SR (2004). Nicotine serves as an effective reinforcer of intravenous drug-taking behavior in human cigarette smokers. Psychopharmacology 175: 134-142.

Hata Y, Nakajima K (2000). Life-style and serum lipids and lipoproteins. J Atheroscler Thromb 7: 177-197.

Ikemoto S (2007). Dopamine reward circuitry: two projection systems from the ventral midbrain to the nucleus accumbensolfactory tubercle complex. Brain Res Rev 56: 27-78.

Jackevicius CA, Tu JV, Ross JS, Ko DT, Carreon D, Krumholz HM (2011). Use of fibrates in the United States and Canada. JAMA 305: 1217-1224.

Justinova Z, Tanda G, Redhi GH, Goldberg SR (2003). Selfadministration of Delta(9)-tetrahydrocannabinol (THC) by drug naive squirrel monkeys. Psychopharmacology 169: 135-140.

Kleijn J, Folgering JH, van der Hart MC, Rollema H, Cremers TI, Westerink BH (2011). Direct effect of nicotine on mesolimbic dopamine release in rat nucleus accumbens shell. Neurosci Lett 493: 55-58.

Le Foll B, Goldberg SR (2004). Rimonabant, a CB1 antagonist, blocks nicotine-conditioned place preferences. NeuroReport 15: 2139-2143.

Lecca D, Cacciapaglia F, Valentini V, Gronli J, Spiga S, Di Chiara G (2006). Preferential increase of extracellular dopamine in the rat nucleus accumbens shell as compared to that in the core during acquisition and maintenance of intravenous nicotine selfadministration. Psychopharmacology 184: 435-446.

Lipski J (1981). Antidromic activation of neurones as an analytic tool in the study of the central nervous system. J Neurosci Methods 4: 1-32.

Liu X, Caggiula AR, Palmatier MI, Donny EC, Sved AF (2008). Cue-induced reinstatement of nicotine-seeking behavior in 
rats: effect of bupropion, persistence over repeated tests, and its dependence on training dose. Psychopharmacology 196: 365-375.

Liu X, Caggiula AR, Yee SK, Nobuta H, Sved AF, Pechnick RN et al (2007). Mecamylamine attenuates cue-induced reinstatement of nicotine-seeking behavior in rats. Neuropsychopharmacology 32: 710-718.

Luchicchi A, Lecca S, Carta S, Pillolla G, Muntoni AL, Yasar S et al (2010). Effects of fatty acid amide hydrolase inhibition on neuronal responses to nicotine, cocaine and morphine in the nucleus accumbens shell and ventral tegmental area: involvement of PPAR-alpha nuclear receptors. Addict Biol 15: 277-288.

Mansvelder HD, McGehee DS (2002). Cellular and synaptic mechanisms of nicotine addiction. J Neurobiol 53: 606-617.

Mascia P, Pistis M, Justinova Z, Panlilio LV, Luchicchi A, Lecca S et al (2011). Blockade of nicotine reward and reinstatement by activation of alpha-type peroxisome proliferator-activated receptors. Biol Psychiatry 69: 633-641.

Melis M, Carta S, Fattore L, Tolu S, Yasar S, Goldberg SR et al (2010). Peroxisome proliferator-activated receptors-alpha modulate dopamine cell activity through nicotinic receptors. Biol Psychiatry 68: 256-264.

Melis M, Pillolla G, Luchicchi A, Muntoni AL, Yasar S, Goldberg SR et al (2008). Endogenous fatty acid ethanolamides suppress nicotine-induced activation of mesolimbic dopamine neurons through nuclear receptors. J Neurosci 28: 13985-13994.

Moreno S, Farioli-Vecchioli S, Cerù MP (2004). Immunolocalization of peroxisome proliferator-activated receptors and retinoid $\mathrm{X}$ receptors in the adult rat CNS. Neuroscience 123: 131-145.

Nisell M, Nomikos GG, Svensson TH (1994). Systemic nicotineinduced dopamine release in the rat nucleus accumbens is regulated by nicotinic receptors in the ventral tegmental area. Synapse 16: 36-44.

O'Sullivan SE (2007). Cannabinoids go nuclear: evidence for activation of peroxisome proliferator-activated receptors. $\mathrm{Br} J$ Pharmacol 152: 576-582.

Panlilio LV, Katz JL, Pickens RW, Schindler CW (2003). Variability of drug self-administration in rats. Psychopharmacology 167: 9-19.

Panlilio LV, Thorndike EB, Schindler CW (2008). A stimuluscontrol account of regulated drug intake in rats. Psychopharmacology 196: 441-450.
Paxinos G, Watson C. The Rat Brain in Stereotaxic Coordinates. Academic Press: San Diego, CA; (2007).

Pistis M, Melis M (2010). From surface to nuclear receptors: the endocannabinoid family extends its assets. Curr Med Chem 17: 1450-1467.

Public Health Service Guideline Update Panel, Liaisons, and Staff (2008). Treating tobacco use and dependence: 2008 update US Public Health Service Clinical Practice Guideline executive summary. Respir Care 53: 1217-1222.

Pontieri FE, Tanda G, Orzi F, Di Chiara G (1996). Effects of nicotine on the nucleus accumbens and similarity to those of addictive drugs. Nature 382: 255-257.

Rose JE (2008). Disrupting nicotine reinforcement: from cigarette to brain. Ann N Y Acad Sci 1141: 233-256.

Scherma M, Panlilio LV, Fadda P, Fattore L, Gamaleddin I, Le Foll $B$ et al (2008). Inhibition of anandamide hydrolysis by cyclohexyl carbamic acid 3'-carbamoyl-3-yl ester (URB597) reverses abuse-related behavioral and neurochemical effects of nicotine in rats. J Pharmacol Exp Ther 327: 482-490.

Shiffman S (1982). Relapse following smoking cessation: a situational analysis. J Consult Clin Psychol 50: 71-86.

Smith JW, Stolerman IP (2009). Recognising nicotine: the neurobiological basis of nicotine discrimination. Handb Exp Pharmacol 192: 295-333.

Solinas M, Scherma M, Fattore L, Stroik J, Wertheim C, Tanda G et al (2007). Nicotinic alpha 7 receptors as a new target for treatment of cannabis abuse. J Neurosci 27: 5615-5620.

Tian Q, Grzemski FA, Panagiotopoulos S, Ahokas JT (2010). Peroxisome proliferator-activated receptor alpha agonist, clofibrate, has profound influence on myocardial fatty acid composition. Chem Biol Interact 160: 241-251.

Ungless MA, Magill PJ, Bolam JP (2004). Uniform inhibition of dopamine neurons in the ventral tegmental area by aversive stimuli. Science 303: 2040-2042.

World Health Organization (2011). WHO Report on the Global Tobacco Epidemic, 2011: Warning About the Dangers of Tobacco. World Health Organization: Geneva.

Wouda JA, Riga D, De Vries W, Stegeman M, van Mourik Y, Schetters D et al (2011). Varenicline attenuates cue-induced relapse to alcohol, but not nicotine seeking, while reducing inhibitory response control. Psychopharmacology 216: 267-277. 